\title{
The Impact of a Customer Discovery Boot Camp on Puerto Rico's Startup Ecosystem
}

\author{
Monica Novoa, MBA ${ }^{1}$, Katerina Sánchez Roig, Bachelor ${ }^{2}$, B. David Bridges, $\mathrm{MSc}^{3}$, Keith McGreggor, $\mathrm{PhD}^{4}$, and \\ Patricia Ramírez Gelpi, LL.M. ${ }^{5}$ \\ ${ }^{1}$ University of San Francisco, USA, monica.novoa@innovate.gatech.edu, ${ }^{2}$ Fairfield University, USA, ksanchez@guayacan.org \\ ${ }^{3}$ Georgia State University, USA, david.bridges@innovate.gatech.edu, ${ }^{4}$ Georgia Institute of Technology, USA, \\ keith.mcgreggor@gatech.edu \\ ${ }^{5}$ George Washington University, USA, pramirez@guayacan.org
}

\begin{abstract}
This paper presents the results of the first impact study of the Innovation-Corps Puerto Rico (ICPR) program. ICPR is a customer discovery boot camp program for entrepreneurial teams offered by Grupo Guayacán, Inc. The program was launched in 2015 and this study evaluated the program's impact from the first to the $10^{\text {th }}$ cohort completed in 2020. The main exploratory objective was to track the teams' start-up journey, measure their progress, and evaluate the overall impact of ICPR on the teams' evolution. To achieve this, the study was designed as an in-depth longitudinal research that involved a survey and follow-up interviews with entrepreneurial teams. The research also sought to provide evidence of ICPR's role as a cornerstone of Puerto Rico's entrepreneurship ecosystem, a key component of the Georgia Tech Lean Startup Ecosystem ${ }^{T M}$ model, and a successful showcase of public-private sector collaboration. The research results provide strong evidence of the positive impact of ICPR on an entrepreneurial team's journey as they moved from an idea or concept through a process of validation and eventually startup creation.
\end{abstract}

Keywords - Evidence-based entrepreneurship, I-Corps, Customer Discovery, Georgia Tech Lean Startup Ecosystem ${ }^{T M}$ model.

\section{INTRODUCTION}

Puerto Rico's economy has been devastated by a deep and prolonged depression since 2006, two years before the global financial crisis. This economic situation has had a dramatic impact on employment and per capita income. The impact of two major hurricanes, Irma and María, in September 2017, followed by the earthquakes in early 2020, have resulted in further severe economic distress; however, in recent years, despite highly challenging economic conditions, startup and entrepreneurial activities have continued their steady development. Entrepreneurship has begun to emerge as a viable alternative for individuals to attain financial stability and better opportunities for themselves, their families, and communities.

In late 2012, the Puerto Rico Science, Research, and Technology Trust (Trust) engaged with the Georgia Institute of Technology (Georgia Tech) to assess the innovation

Digital Object Identifier (DOI):

http://dx.doi.org/10.18687/LEIRD2021.1.1.43

ISSN: 2414-6390 ISBN: 978-958-52071-9-6 ecosystem of the island and the role of its universities. In June 2013, Georgia Tech provided a detailed report to the Trust entitled, Puerto Rico Innovation Center for Technology Inspired Economic Development. Georgia Tech's recommendations were directed at stimulating research, education, and economic development through the public and private university systems.

A key finding from the Georgia Tech study was that Puerto Rico's startup ecosystem was in a nascent stage with few Entrepreneurship Support Organizations (ESOs) including incubators, accelerators, proof-of-concept centers, and mentorship programs. In addition, government programs for small and medium businesses were scarce. There were few entrepreneurship success stories across the island, which made entrepreneurship an even less attractive career choice. However, there was also a limited pool of talent for mentoring entrepreneurs and startup companies. Lastly, there was limited seed and gap funding for startups. The startup and innovation ecosystem lacked connection between sources of innovation, pools of entrepreneurs, groups of mentors, and sources of gap funding

These findings were aligned with the Global Entrepreneurship Monitor (GEM) Puerto Rico report, which has been conducted consecutively since 2013 [1]. The annual results of this study depict the changes in entrepreneurial activity and the socioeconomic aspects related to entrepreneurship in the island. In 2013, only 17.9 percent of the respondents to the GEM Puerto Rico survey affirmed that starting a new business was considered a desirable professional career choice. This was the lowest percentage among the 50 countries that participate in the study. In addition, only 13.1 percent of the respondents had the intention to start a new business in the next three years. Under this panorama, it was evident that Puerto Rico's startup ecosystem needed a program to infuse the island with an entrepreneurial mindset and train future entrepreneurs with proven methodologies and skills.

\section{FRAMEWORK}

A. The Georgia Tech Lean Startup Ecosystem (GT-LES) ${ }^{T M}$ Model 
The GT-LES ${ }^{\text {TM }}$ model has been created by a group of Georgia Tech's innovation led economic development practitioners from their experience working in nascent ecosystems on five continents since 2010 . It is a methodology to support the development of nascent entrepreneurship ecosystems using Evidence-based Entrepreneurship (EBE) principles such as lean start-up, customer discovery, and the business model canvas, among others. EBE is defined as the practice of hypothesizing, testing, and validating to create a business model [2].

The GT-LES ${ }^{\mathrm{TM}}$ model focuses on nascent ecosystems with the intent of growing technology based, global ventures using a lean approach to leverage financial and human resources toward accelerating high-potential teams. A high-potential team is considered one that has a customer validated product; is targeting large global markets or is "born global," is technology-based and has a strong team. The GT-LES ${ }^{\mathrm{TM}}$ model is a balanced three stage approach that starts with the crucial FOSTER stage dedicated to nurturing the creation and participation of large numbers of entrepreneurial teams; it continues to the VALIDATE step of identifying high-potential start-up teams from the Foster stage using EBE techniques, and it ends with the PROPEL stage during which the critical high-potential start-ups are embraced and scaled with support programs [3].

Since 2012, Georgia Tech has worked with willing and committed partners in Puerto Rico on the construction of an island-wide innovation and startup ecosystem applying the GT-LES ${ }^{T M}$ model. To date, these efforts have contributed to the attraction of more than $\$ 22.3$ million in public and private funding injected into Puerto Rico's innovation ecosystem. Furthermore, these efforts have generated more innovation, promoted free flow of innovation, inculcated the ecosystem with a common language and a common set of entrepreneurship tools, have validated high-potential ventures, and have propelled those ventures with specific support programs.

Grupo Guayacán, Inc. (Guayacán), in collaboration with Georgia Tech and key local allies, started applying the GT$L E S^{T M}$ model with the I-Corps Puerto Rico program in 2015 to help entrepreneurs build a scalable business model around an innovative idea. In five years, the program has generated public interest, attracted entrepreneurs from all parts of the community, and began a process of cultural and mindset transformation. In addition, Guayacán offers other programs to support entrepreneurs as they scale their ventures, including: EnterPRize, a business competition that supports entrepreneurial teams as they accelerate their ideas; the IDEA Seed Fund that provides gap funding to early-stage teams; and the Guayacán Venture Accelerator (GVA) to support highgrowth or corporate research \& development teams.

\section{B. The Innovation-Corps (I-Corps) Puerto Rico Customer Discovery Bootcamp}

I-Corps Puerto Rico (ICPR) is a Customer Discovery boot camp offered by Guayacán that helps entrepreneurial teams validate the feasibility of their business ideas by obtaining real-time customer feedback. ICPR was launched in 2015 with support from a grant from the U.S. Economic Development Administration to hold a National Science Foundation (NSF) Innovation Corps (I-Corps) cohort on the island. The program was the first of its kind, offering the I-Corps content to a broader community of entrepreneurs, not just NSF funded academic teams, and in a predominantly Latin culture, jointly taught with bilingual content in English and Spanish. Since then, Guayacán has continued to offer ICPR annually with support from local organizations like the Puerto Rico Science, Technology, and Research Trust (TRUST), Department of Economic Development \& Commerce (DDEC), Puerto Rico Industrial Development Company (PRIDCO), and others.

The program is executed through a partnership with Georgia Tech which manages the node for NSF's I-Corps for the Southeastern region of the U.S. (I-Corps South). ICPR is designed for small teams of entrepreneurs (2-3 members) looking to validate innovative business ideas and build scalable business models. Through the intensive five-week program, each team learns about their target markets by conducting more than 100 customer discovery interviews with potential customers and other market influencers. This feedback informs each team's decision on whether to proceed, pivot or discard their business idea by the program's conclusion.

The program is unique because it teaches participants a new way to think about entrepreneurship where extensive customer discovery is used to find a compelling business model before deciding on whether to launch a start-up business. This methodology helps the team avoid wasting valuable time, money, and resources on untested ideas which may be more likely to fail [4]. The program is also well known for its boot camp-like approach, taking teams from idea to a go/no-go decision in a relatively short time frame through intensive work and ongoing feedback from the teaching team and a group of mentors which accompany each team through the process. The boot camp format allows teams to participate in multidimensional entrepreneurship activities and candid discussions in a less structured environment, facilitating communication between participants, instructors, and mentors, which is fundamental for business idea generation, development, and validation [5]. Furthermore, studies have shown that the capacity building and mentoring components of an entrepreneurship boot camp have significant impact on the entrepreneurial capabilities and competencies of participants [6]. 
ICPR is completely industry agnostic, impacting teams from a wide variety of economic sectors and industry groups. A typical cohort includes a combination of community start-up teams, university-based teams, and R\&D teams from existing businesses. This mix of industries and backgrounds provides for unparalleled peer learning opportunities, an experience which is unmatched by other entrepreneurial programs in Puerto Rico.

Between the 2015 ICPR pilot cohort and December 2020, Guayacán has led the delivery of 11 cohorts which have graduated 180 entrepreneurial teams impacting over 658 individual participants. Given its streamlined nature, Guayacán has been able to take ICPR to several locations throughout the island of Puerto Rico. To date, ICPR has been offered in five different locations: San Juan, Carolina, Gurabo, Ponce and Mayagüez. In 2020, the two sessions of the program were conducted virtually due to the COVID-19 pandemic. Approximately 80 percent of graduated teams are still actively working on their projects and have raised more than $\$ 15$ million in local/federal grants and other funding, to continue developing their ventures (Fig. 1). Many ICPR graduates have moved on to other entrepreneurial support programs, including those offered by Guayacán, such as EnterPRize $^{1}$ and the Guayacán Venture Accelerator $(\mathrm{GVA})^{2}$, as well as other ecosystem partners such as Parallel1 $8^{3}$ and Startup.PR ${ }^{4}$.

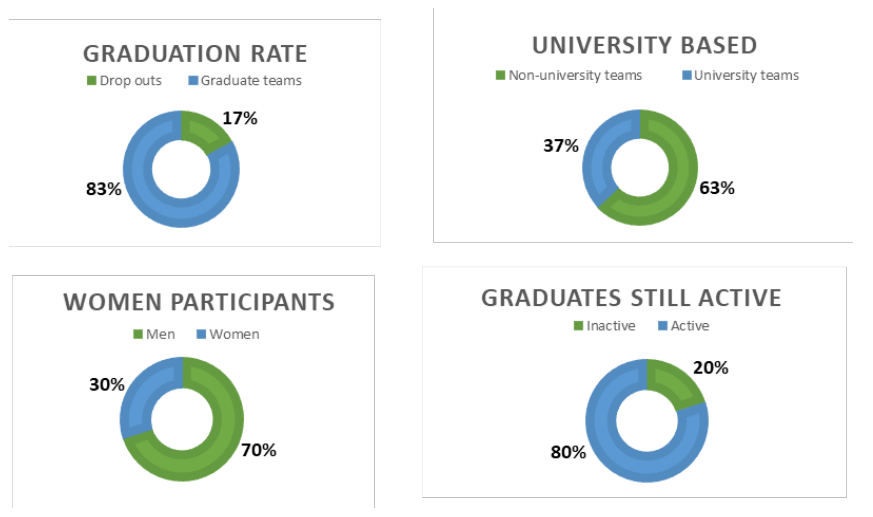

Fig. 1 I-Corps Puerto Rico Impact Metrics 2015 - 2020

\section{METHODOLOGY}

Guayacán engaged with Georgia Tech's Enterprise Innovation Institute in 2020 to conduct the first impact study of I-Corps Puerto Rico (ICPR) since it was launched in 2015. The study was partially funded by the Economic Development Administration (EDA) University Center program of Georgia

\footnotetext{
${ }^{1}$ EnterPRize https://guayacan.org/our-programs/enterprize-businesscompetition/

${ }^{2}$ Guayacán Venture Accelerator (GVA) https://guayacan.org/ourprograms/guayacan-venture-accelerator/

${ }^{3}$ Paralell18 https://parallel18.com/

${ }^{4}$ Startup.pr http://startup.pr/
}

Tech. This paper presents the findings from the impact study conducted with the 157 entrepreneurial teams that participated in one of the ten ICPR cohorts between 2015 and September 2020. The study did not include 23 teams that were participating in the 11 th cohort of the program between in October and December 2020. The study was designed as a longitudinal research that involved repeated observations of the same variables (e.g., people) over periods of time with the purpose to analyze changes in behavior, consumer trends, life events, development milestones, etc. In this case, the study's variables are the entrepreneurial teams that have graduated from ICPR. Using an online survey, and follow-up interviews, key metrics of business growth, both before and after participation in ICPR, were obtained to understand how the program contributed to the teams' entrepreneurial journey. The study was conducted over a period of 6 months from July to December 2020.

The study's main exploratory objective was to track the teams' start-up journey, measure their progress, and evaluate the overall impact of ICPR on the teams' evolution. The study did not intend to evaluate the ideas or concepts that the teams were exploring during their participation in the program, or their subsequent versions, as ICPR is a program designed to build capacity on the entrepreneurs and equip them with skills so they can validate the commercial potential of any idea. The study also set out to provide evidence of ICPR's role as a cornerstone of Puerto Rico's entrepreneurship ecosystem, a key component of the Georgia Tech Lean Startup Ecosystem $^{T M}$ model, and a successful showcase of cross sector collaboration. A survey was used to collect input from the ICPR graduate teams. The survey included a series of questions related to the teams' trajectory, and their experience before and after ICPR. The survey also included several openended questions to allow anecdotal answers or qualitative data. Follow up interviews were conducted with a select group of entrepreneurial teams to further validate some of their answers. Quantitative and qualitative data collected from the survey were analyzed and presented in a report.

\section{A. Survey Sample and Demographics}

The survey was distributed to 157 graduated teams (cohorts 1 through 10) via group and personalized emails inviting them to provide their input by completing the online survey. An email with a link to the survey URL was sent to the teams in the sampling frame to invite them to participate in the study. Respondents completed the survey online, with responses automatically captured in a secure database. Overall, 64 teams completed the survey; representing a response rate of 40.76 percent of the total number of graduate teams invited to answer the survey. This response rate is significantly higher than the average expected response rate of external surveys of 20 percent. Most of the survey respondents participated in the $8^{\text {th }}, 9^{\text {th, }}$ and $10^{\text {th }}$ cohorts. Responses corresponding to these cohorts make up 48.66 percent of the total responses. This 
over representation of teams graduating from recent editions of the program is in line with our experience with similar alumni-based surveys.

The data analysis was divided into before and after participating in ICPR. Section IV. includes the analysis of survey questions regarding the origins of the teams such as how the team was created, how long had the team members been working together, how they came up with the idea, how much funding they had before participating in ICPR, among others. Section V. focuses on the analysis of the team's progress after graduating from ICPR. The key metrics in this section relate to business creation and growth and are aimed at better understanding how ICPR prepared the team with the right entrepreneurial skills and contributed to their growth.

\section{TEAMS BEFORE I-CORPS PUERTO RICO}

This section includes the analysis of the data and feedback gathered from respondents about their teams before participating in ICPR. For this study, it was important to understand how teams were formed; how long they had been working together and how was the idea identified; what industry sector did the ideas belong to, and in what other ecosystem programs had the teams participated. In addition, the study gathered important information about the funding sources that ICPR teams had utilized before taking the program. Most of the teams ( 82.82 percent) had been working together for less than a year as shown in Fig.2.

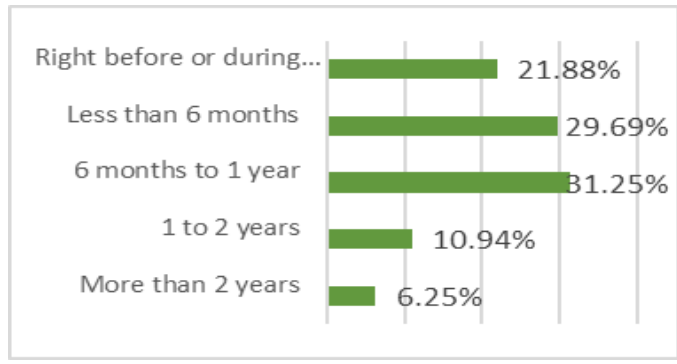

Fig. 2 Time Working on the Idea before ICPR

These findings are consistent with the fact that ICPR is marketed towards teams who are just starting to work on a new business idea and need to apply effective tools to validate their idea's commercial potential. As detailed in Fig. 3, most of the teams (53 percent) reported market validation and business idea testing as their main reason for coming together as a group. This finding is consistent with ICPR's mission of supporting the customer discovery journey of idea-stage entrepreneurial teams.

An important element of an entrepreneurship ecosystem is the availability of different sources of funding. None of the teams indicated receiving venture capital, corporate investment, or private loans. The total amount raised before ICPR is $\$ 6,593,000$ (Table 1). It is necessary to clarify that of the 64

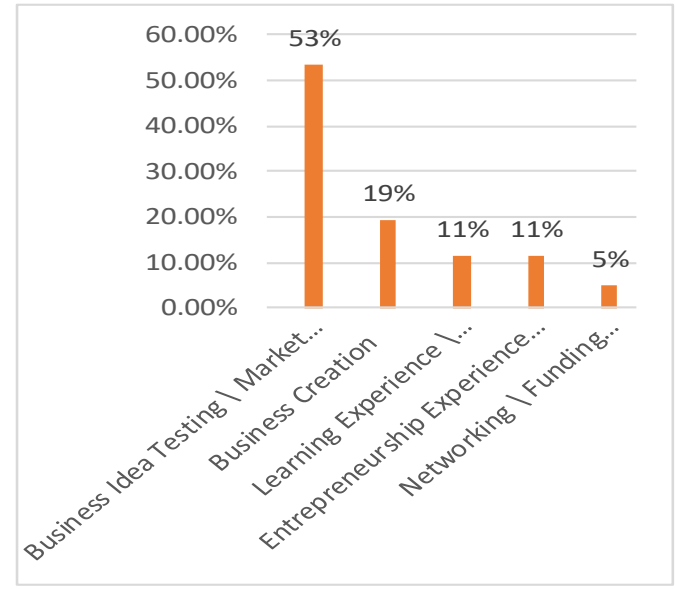

Fig.3 Reason for Creating the Team

teams that answered the survey, there was an outlier that indicated having raised $\$ 4$ million in funding from a public source before the ICPR. This was a unique case that made the public funding source disproportionally high compared to the other sources reported in this study.

Table 1. Total Funds Raised before ICPR

\begin{tabular}{|l|r|}
\hline Source & $\begin{array}{r}\text { Amount } \\
\hline \text { Self-funding }\end{array}$ \\
\hline Friends and family & $\$ 125,000$ \\
\hline Angel investment & $\$ 340,000$ \\
\hline $\begin{array}{l}\text { Public funds } \\
\text { (e.g. Gov grants) }\end{array}$ & $\$ 5,057,000$ \\
\hline $\begin{array}{l}\text { Accelerators, Incubators, } \\
\text { Competitions }\end{array}$ & $\$ 184,000$ \\
\hline Other & $\$ 124,000$ \\
\hline Total & $\$ 6,593,00$ \\
\hline
\end{tabular}

Self-funding plus friends and family combined represented the first source of funding with a total amount of $\$ 888,000$. The second source was public funds with a total amount of $\$ 5,057,000$ including the team that received a $\$ 4$ million grant, but even if this grant was not counted, public funds are still the second most available funding source. The third source was accelerators, incubators, and competitions with a total of $\$ 184,000$. This is an indication that most teams are leveraging their own personal funds along with friends a family, which is normal in many ecosystems; however, there is an opportunity for the local ecosystem leaders and entrepreneurship support organizations (ESOs) to establish new programs focused on increasing the availability of public funds as well as funds offered by accelerators, incubators, and competitions.

\section{TEAMS AFTER I-CORPS PUERTO RICO}

This section covers the analysis of data and feedback gathered from respondents about their team's evolution after graduating from the ICPR. Of the 64 teams that answered the survey, 31 
teams indicated that a company had been created based on the project idea or 48.43 percent. This is an impressive success metric for ICPR which is close to the National Science Foundation (NSF) I-Corps average company creation ratio of 54.29 percent. Since the NSF launched I-Corps in 2011, a total of 1,908 teams have participated and 1036 start-up businesses formed [7]. Fig. 4 show the total number of companies created by ICPR graduate teams and the breakdown by year of participation.

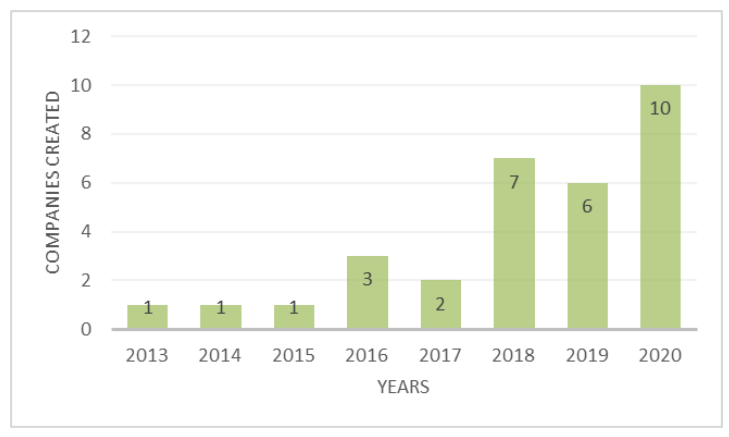

Fig. 4 Companies Created by Year

The study also asked if the teams had continued working with the mentor that they had during the ICPR program, and if they had not, what were the reasons. The goal was to gather insight about the possible challenges that teams faced to establish a good relationship with their mentors and potential opportunities to strengthen the mentor network. This question was presented only to the 31 teams that had created a company. Fig. 5 shows that 67.82 percent of the teams that answered this question indicated that they had not continued to work with their ICPR mentor. The most common reason for not continuing to work with the ICPR mentor was that they lost contact, while few teams answered that they had problems to coordinate meetings or did not have a good match in interests.

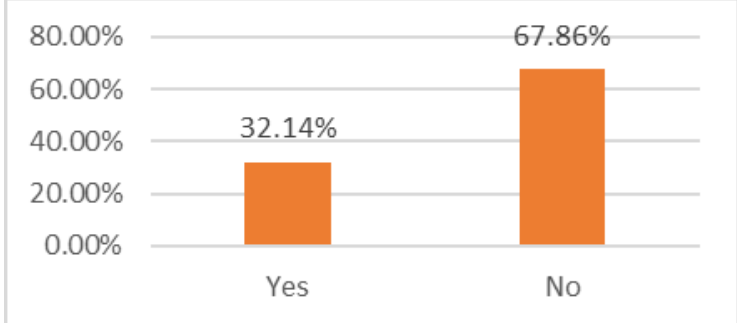

Fig 5 Team-Mentor Collaboration after ICPR

While ICPR mentors are not expected to continue supporting graduate teams after the program, the answers reflect an opportunity for Guayacán to foster stronger bonds between teams and mentors, so that ideally, these relationships continue to evolve more organically over time. This is especially important because research shows that mentoring is one the most helpful ways to facilitate the transfer of business knowledge and experiences to the entrepreneur so they can develop a stronger skill set.[8].

The 31 companies created after ICPR have 11 full-time and 39 part-time employees which represents a total of 50 jobs created as shown in Fig. 6. These jobs offer opportunities for better economic conditions and high-quality employment, and it is Guayacan's long-term hope that ICPR helps plant the seed for future high-growth companies which create many more quality jobs in Puerto Rico.

The 31 companies reported having a total of 52 owners. Thus, when adding 52 owners, plus 50 full-time and part-time employees, the 31 ICPR graduate companies have created a total of 102 jobs in five years.

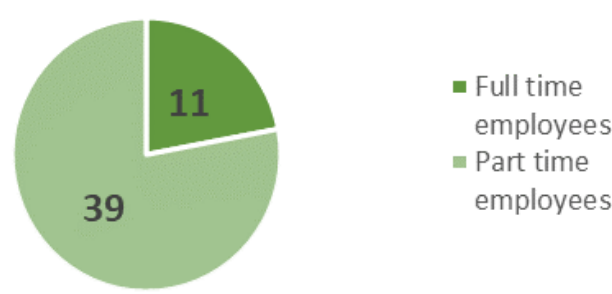

Fig. 6 Jobs Created (*)

(*) Jobs created in addition to the company owners.

These results are even more important when compared to recent studies that show there is a significant number of entrepreneurships in the Latin American and Caribbean region, but most are small in scale and show low dynamism in generating new jobs. About $75 \%$ are classified as subsistence and only $25 \%$ have the potential to grow, generate employment and innovate [9]. As the companies founded by ICPR graduates are considered as high-potential, because they have a validated business idea that is innovative and a large global market, they undoubtedly have greater probabilities to contribute to the long-term economic growth in Puerto Rico.

Of the 31 companies, only 12 have generated revenue in the most recent Fiscal Year, with the majority (nearly 60 percent) earning between $\$ 0$ and $\$ 25,000$ dollars, and another third earning from $\$ 25,001$ to $\$ 75,000$. Only one company answered receiving earnings of more than $\$ 200,000$. None of the companies reported earnings in the range between $\$ 75,001$ and $\$ 100,000$, or between $\$ 100,001$ and $\$ 200,000$. These revenue levels are in line with the expectation for companies that are in idea stage, working on product development, and acquiring paying customers ${ }^{5}$. Fig. 7 includes only the revenue ranges that were selected by respondents.

\footnotetext{
${ }^{5}$ https://davidcummings.org/2015/07/17/start-up-stages-by-revenue/
} 


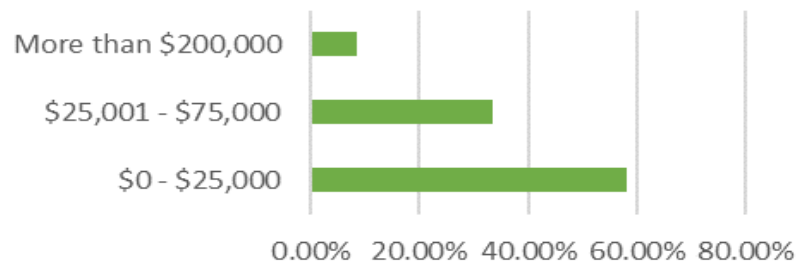

Fig. 7 Revenues Generated by Companies

The largest source of funding after ICPR continued to be selffunds with a total amount of $\$ 1,525,600$. Combining selffunding with friends and family, the total is $\$ 1,854,600$. This means that ICPR teams are using more of their own personal savings and money borrowed from friends and family to finance their entrepreneurial ventures as compared to other funding sources. The second source of funding is public funds for a total of $\$ 617,000$. These are government grants from programs like the national NSF I-Corps and the SBIR/STTR, and local programs from the Puerto Rico Science, Technology, and Research Trust among others. None of the teams indicated receiving venture capital or corporate investment. The total amount of funds raised from the different sources was $\$ 3,885,970$. Table 2 show additional details.

\begin{tabular}{l|r|}
\multicolumn{2}{|c|}{ Table 2. Total Funds Raised after I-Corps } \\
\hline $\begin{array}{l}\text { Source } \\
\text { Self-funding }\end{array}$ & \begin{tabular}{c} 
Amount \\
\hline Friends and family
\end{tabular} \\
\hline $\begin{array}{l}\text { Angel investment } \\
\text { Public funds } \\
\text { (e.g. Gov grants) }\end{array}$ & $\$ 329,600$ \\
\hline $\begin{array}{l}\text { Private loans } \\
\text { (e.g. Commercial bank }\end{array}$ \\
$\begin{array}{l}\text { loans) } \\
\begin{array}{l}\text { Accelerators, Incubators, } \\
\text { Competitions }\end{array}\end{array}$ \\
\hline $\begin{array}{l}\text { Other } \\
\text { Total }\end{array}$ & $\$ 519,500$ \\
\hline
\end{tabular}

It is important to clarify that these are funds raised only by the survey respondents. In addition, the other graduate teams that did not answer the survey have raised $\$ 4,667,500$ per Guayacán's metrics system. Adding to this the total amount of $\$ 6,593,000$ raised before the program plus $\$ 3,885,970$ raised after graduation, the total funds raised by ICPR graduate teams to $\$ 15,196,470$ in the first five years of the program. The respondents have raised funds from different financing sources such as self-funding; friends and family; angel investment; public funds (e.g., Government grants); private loans (e.g., Commercial bank loans); and accelerators, incubators, competitions. However, ICPR graduate teams have not raised funds yet from venture capital, or corporate investment sources, which is consistent with the focus of the program on teams that are at the idea or concept stage and usually are not funded by venture or corporate investors.

The commercialization of intellectual property is another of the original objectives of ICPR. The survey asked the 31 teams that had created a company if they had any Intellectual Property (IP). The most common IP instrument among the companies that answered the survey was a Non-disclosure Agreement (NDA) with 46.38 percent of companies reporting having a total of 64 NDAs in place (Fig.8). The second most used IP form was the Trade Secrets with 25.36 percent of respondents saying they hold 35 of these instruments. And the third IP type most used was the Copyrights with 15.94 percent of the companies holding 22 of these.

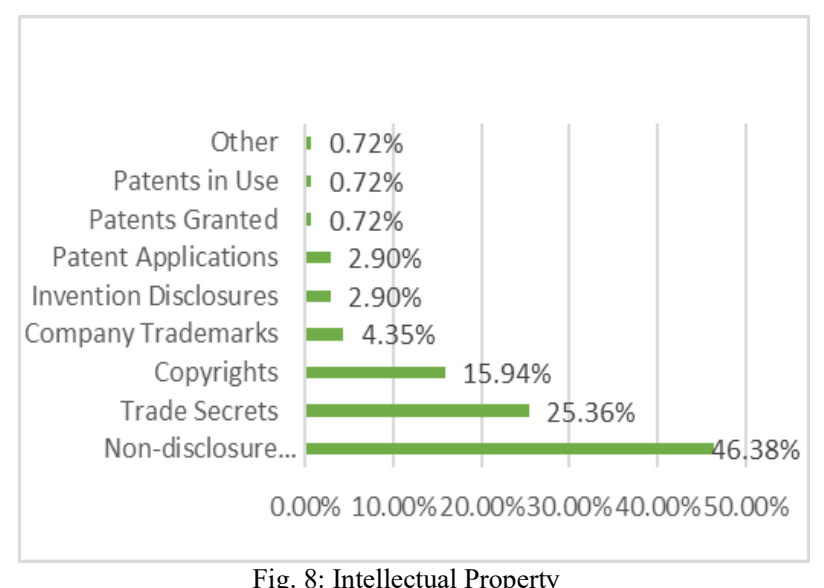

Another important finding was the evidence that ICPR has contributed to a more interconnected ecosystem with teams that start their entrepreneurial journey at ICPR and then transition to subsequent ecosystem programs. Fig. 9 shows the continuum of programs before and after ICPR per the survey results. It is notable that survey respondents had participated in only 12 programs before ICPR and went on to participate in 18 programs after culminating ICPR. To place this result in context, per Colmena66's Tu Camino Empresarial ${ }^{6}$ tool, there are currently 163 programs in total offered to entrepreneurial teams in Puerto Rico. Tu Camino Empresarial categorizes the programs according to the following four business stages: Stage 1 - Idea, Concept; Stage 2 - Proof of Concept, Prototype, Market Entry; Stage 3 - Launch; and Stage 4 Growth, Expansion.

Of the 18 programs that ICPR entrepreneur teams transferred to, 6 took place out of Puerto Rico, and 12 in the island. While it is not ideal that Puerto Rico entrepreneurial teams go to mainland US or other regions to continue developing their businesses, there are some exceptions. One of these exceptions would be participating in the National NSF I-Corps program,

\footnotetext{
${ }^{6}$ Colmena66 Tu Camino Empresarial https://www.colmena66.com/
} 
which is a very prestigious program and teams receive $\$ 50,000$ in funding. While only three of the respondent groups participated in a National Science Foundation (NSF) I-Corps cohort, in total, five graduate teams have participated in this highly prestigious program, each receiving a $\$ 50,000$ grant. This represents a total of $\$ 250,000$ dollars in funding from NSF received by ICPR teams. Building a pipeline of high potential teams to participate in national programs and funding opportunities was one of the original reasons for launching ICPR.

Moreover, the entrepreneurial teams that moved on to other programs in the island took advantage of support programs in different stages according to the Tu Camino Empresarial tool. For example, 15.8 percent of the teams participated in EnterPRize which belongs to Stage 3 - Launch, while 9.9 percent of the teams participated in Parallel18 which falls into Stage 4 - Growth, Expansion. This is an important outcome in line with the GT Lean Startup Ecosystem Model's expectation that as the ecosystem matures, teams would increasingly transfer along the entrepreneurial support programs.

The fact that more than half of the graduate teams go on to participate in other programs, provides more evidence that ICPR has become recognized among entrepreneurs as the first step to take to improve their entrepreneurial skills while validating their business ideas and business models. This fact also goes to show that ICPR graduates are well-positioned as strong applicants to competitive programs both in Puerto Rico and mainland U.S., which grant them access to additional education, resources, and funding.

This interconnectedness between entrepreneur support programs is even more relevant when analyzed in the context of the Latin American and Caribbean entrepreneurship programs and capacity building opportunities for the younger generations. There are many factors that can help drive entrepreneurship in the region in the future, including more support programs, increased financing, and a more flexible regulatory base among others, but perhaps the most important are education and training. As stated in the report, Economic Outlook for Latin America: Youth, Skills and Entrepreneurship, published in 2017 by the Organization for Economic Cooperation and Development (OECD) it is essential to focus efforts on strengthening education systems and promoting lifelong learning, because "while development can stem from different sources, skills and entrepreneurship can empower youth to develop knowledge-intensive economic activities, boost productivity and transform the region's politics as they transition successfully from the world of school to the world of productive work and create that future they seek [10]."

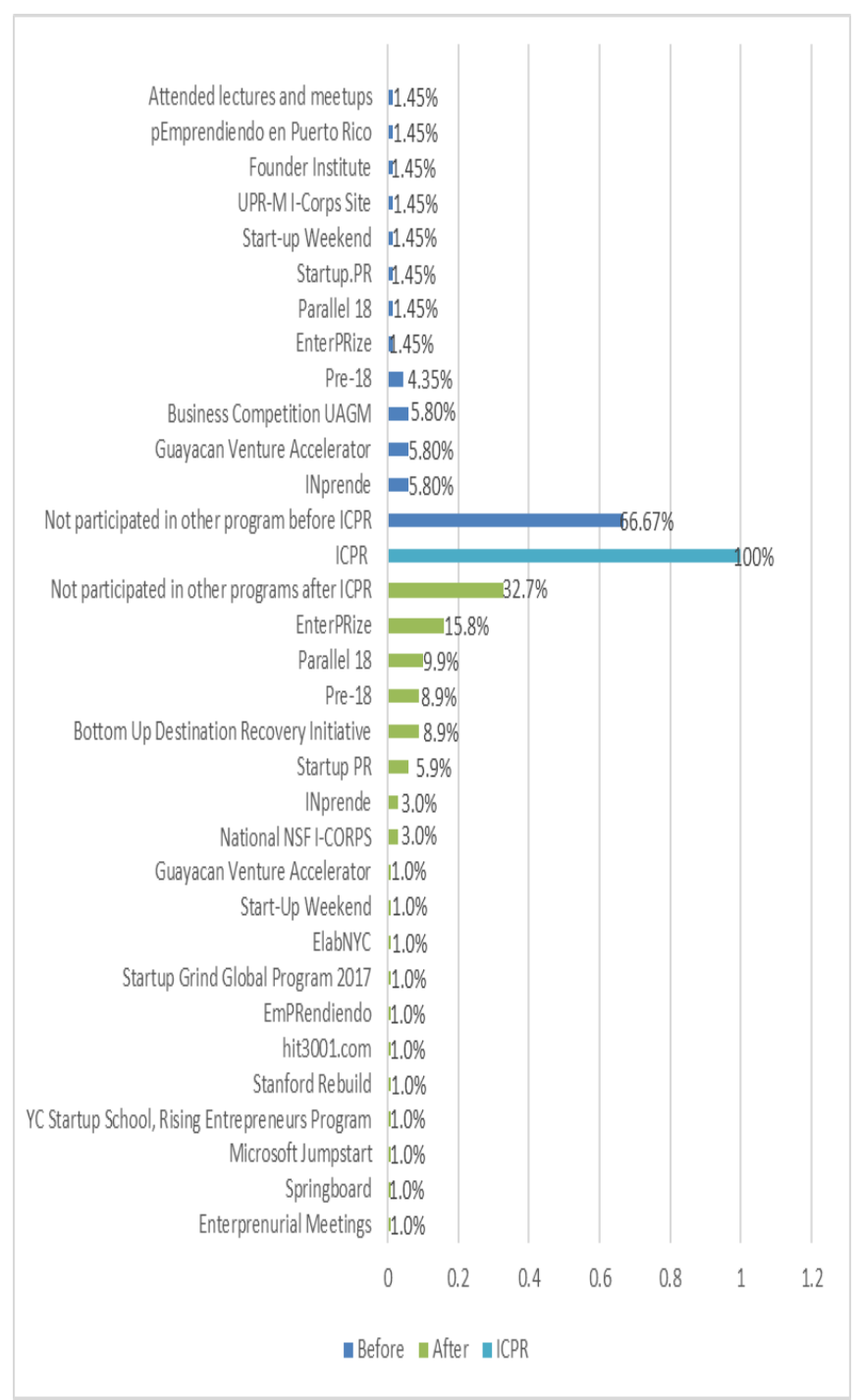

Fig. 9 Continuum of Ecosystem Programs

\section{CONCLUSION}

When Grupo Guayacán started conversations with Georgia Tech in 2014 to bring the National Science Foundations' Innovation Corps (I-Corps) training model to Puerto Rico, their vision was to strengthen the island's nascent entrepreneurship ecosystem with a proven program to equip entrepreneurs with the tools to validate a business idea and its commercial viability. This was the genesis of the I-Corps Puerto Rico (ICPR) program. The long-term vision was for ICPR to become the first step of an entrepreneur's journey and to gradually infuse the ecosystem with a common language and an entrepreneurial mindset. This first impact study of ICPR graduate teams was designed with the objective to track the teams' trajectory and learn how the skills, knowledge and experience acquired during the ICPR have contributed to their growth. Another objective of the study was to determine how many companies had been created by ICPR graduate teams 
and where they were in their journey. Lastly, given the economic development role of ICPR as a program that fosters the commercialization of new ideas, it was important to evaluate the program's economic impact in terms of jobs created, investment raised, and revenues generated by companies.

The survey results provide strong evidence that ICPR has become the first step of Puerto Rico's entrepreneurs in their start-up journey with 82.82 percent of respondents indicating that they had been working on the business idea for less than a year before the program, 53 percent of the teams were created to test a business idea or validate a market, and 19 percent had the goal to start a business. In total, the 64 ICPR teams that participated in the study have created 31 companies. The majority (nearly 60 percent) of the companies reported earning between $\$ 0$ and $\$ 25,000$ dollars, and another third earning from $\$ 25,001$ to $\$ 75,000$. These revenue levels are in line with the expectation for young companies in the idea stage, that are working on product development and toward acquiring paying customers. These are impressive results that clearly support ICPR's mission of training entrepreneurial teams on Evidencebased Entrepreneurship (EBE) concepts, especially customer discovery, so they can validate their ideas and build businesses which are better positioned to succeed.

There are, however, important areas for improvement as significant gaps in the ecosystem were highlighted by the study results. First, ICPR teams indicated not keeping in contact with their mentor after the program. Although ICPR mentors are not expected to continue working with the teams beyond the program, there is an evident need for additional mechanisms to connect teams with successful ecosystem entrepreneurs. Second, most of the teams are leveraging selffunds, and family and friends financial support before and after graduating from the program. Teams reported raising $\$ 888,000$ investment before the program utilizing self-funds, and family and friends, which represented 68 percent of the funding sources available to the teams, while 44.33 percent of the teams reported raising $\$ 1,854,600$ through self-funding, and family and friends after the program. These findings point to the need for additional gap funding options in the ecosystem to support the teams.

ICPR's economic impact was evidenced by key economic development metrics. First, the 31 companies founded by ICPR teams that responded the survey have created 102 jobs between 2015 and 2020. Second, the ICPR graduate teams that answered the survey, reported raising a total of $\$ 10,528,970$ investment from private and public sources. It is important to keep in mind that these were only funds reported by the survey's respondents. In addition, the other graduate teams that did not answer the survey have raised $\$ 4,667,500$ according to Guayacán's metrics system. Therefore, ICPR graduate teams have raised total of $\$ 15,196,470$ investment in the first five years of the program. Graduate teams are working in diverse industry sectors with the top sectors including: Healthcare/Medical, Agriculture \& Food, Education, IT \& Communications, Tourism, Environment, Real Estate, Aerospace, Crowdfunding, Automobiles and Ecommerce.

ICPR's success metrics provide important evidence that training entrepreneurial teams on EBE concepts early on in their journey contributes to quickly identifying high-potential teams and setting them up in the right path to create successful business. This is the main objective of the VALIDATE stage of the Georgia Tech Lean Startup Ecosystem ${ }^{T M}$ model that centers around identifying high-potential start-up teams from the FOSTER stage using EBE techniques. The goal in this stage is to direct the scarce resources of a nascent ecosystem toward a proven methodology, like the I-Corps or similar models, to put as many teams as possible through customer discovery and market validation in a short period of time. The teams that validate their ideas and commercial benefit, then move on to subsequent ecosystem programs in the PROPEL stage. Eventually, as more high-potential teams move from the VALIDATE to the PROPEL stage, the ecosystem matures and in turn successful entrepreneurs start taking leadership roles and giving back to support the new generations of entrepreneurs.

The success of ICPR is also a great example of the increased collaboration between private, public, and non-profit sectors in Puerto Rico in support of its entrepreneurship ecosystem. Guayacán has built an extensive network of partners that participate regularly in their programs in different capacities, from mentors, to judges, and investors, providing invaluable support to the entrepreneurial teams. In addition, support from public and government agencies like the Puerto Rico Industrial Development Company (PRIDCO) and others, has made possible for Guayacán to continue offering ICPR over the years. In this sense, ICPR is making significant contributions to the strengthening of Puerto Rico's innovation and entrepreneurship ecosystem by improving public, private, and non-profit coordination for the development of capacity building programs for entrepreneurs.

The results are outstanding and strongly reflect ICPR's significant impact on the teams' trajectory and the economic development of Puerto Rico, which solidifies the importance of the program as a key driver of the island's entrepreneurship ecosystem. The dream that started in 2014 with the goal of bringing to Puerto Rico the successful NSF I-Corps model, has evolved, and matured over the years into a cornerstone of the entrepreneurs' journey in the island. The impact of the ICorps Puerto Rico is a testament to Guayacan's vision and determination and its continued dedication to the education and development of local entrepreneurs with the goal of helping the Puerto Rican economy grow. 


\section{RECOMMENDATIONS}

\section{A. Increase early-stage non-dilutive funding}

An important finding from the study is that ICPR graduate teams have funded their ventures primarily with personal investments and through family and friends, while some have used public funds. This reflects an ecosystem gap and need for greater variety of early-stage funds. In the early stage of a venture, the Idea stage in the Colmena66 Tu Camino Empresarial and the VALIDATE stage in the Georgia Tech Lean Startup Ecosystem ${ }^{T M}$, the team is working on idea validation and the business is not earning sufficient revenue, or no revenue at all, as their product or service is not fully developed. In this stage, the entrepreneurs need to access nondilutive financial options without losing ownership or equity in their fledgling business. A shortage of non-diluting capital can be considered as a market failure, which occur when a market cannot create a certain desired activity on its own. In these cases, the government must intervene with public policies to solve the market failure. The study's findings point to an opportunity for Puerto Rico ecosystem's public sector leaders and stakeholders to work together on designing and implementing public policies that are favorable for early-stage entrepreneurs to access non-dilutive funding.

\section{B. Continue the study of ICPR's impact}

This study demonstrated ICPR's impact and its important role in the entrepreneurial journey of Puerto Rico's entrepreneurs. Furthermore, the study provided evidence of the program's tremendous economic impact as a driving force behind the early stages of high-potential ventures. It is recommended to continue performing this study on an annual basis, or every two ICPR cohorts, to measure results and reinforce the data about the program's impact. In addition, it is recommended to conduct a follow-up in-depth study every year with a subset of ICPR graduates utilizing an individualized format to analyze their unique trajectory and document a series of success stories that could serve not only as inspiration to future entrepreneur generations, but also as additional evidence of the ICPR's integration and contribution to the success of the island's entrepreneurship ecosystem. The annual longitudinal study and individualized success stories would continue to provide evidence about ICPR's impact measured by output metrics, in addition to relevant insights about the ecosystem dynamics and gaps to be addressed for the long-term success of the island's entrepreneurship ecosystem. These evidence-based insights would serve as important input to Puerto Rico's ecosystem stakeholders and policy makers for future design and implementation of public policies to support entrepreneurship and economic growth.

\section{Communicate ICPR's benefits to communities}

The ICPR's program has proven to be a successful model to help early-stage entrepreneurial teams validate a business idea, and to stimulate an entrepreneurial mindset in a nascent ecosystem. Further considering that ICPR was the first program modeled after the NSF I-Corps and opened to community entrepreneurs (in addition to academic teams) in a predominantly Latin culture, it is recommended to communicate and amplify this message with the goal to continue positioning the ICPR as the cornerstone of an entrepreneur's journey in Puerto Rico and to share best practices on developing nascent entrepreneurship ecosystems with other regions around the world.

\section{ACKNOWLEDGMENT}

This research has been partially supported by the Georgia Tech Economic Development Administration (EDA) University Center. In addition, Grupo Guayacán contributed part of the funding, data and resources to support the research activities.

\section{REFERENCES}

[1] Global Entrepreneurship Monitor (GEM) 2019 Report, Universidad de Puerto Rico, Facultad de Administración de Empresas. [Online] Available: http://gem.uprrp.edu/

[Accessed: July. 20, 2021]

[2] H.M. Neck, C. P. Neck, and E. Murray, Entrepreneurship: the practice and mindset. 2nd ed. Thousand Oaks: SAGE Publishing, 2020.

[3] B.D. Bridges, "Creating Innovation Ecosystems: Utilizing Lean Techniques to Energize a Nascent Startup Ecosystem A Puerto Rico Case Study," The International Conference of Knowledge and Innovation, ciKi, Bogotá, Colombia, November 2016.

[4] S. Martin Henderson, L. Attruia and M. Bolen Heffner, "Coaching Students and Teams to Listen to Customer Needs," in IEEE Potentials, vol. 40, no. 3, pp. 28-34, May-June 2021, doi: 10.1109/MPOT.2021.3055193.

[5] C.C.Y Kwong, et al., "The Role of Environment in Fostering Conductive Entrepreneurial Learning: Teaching the 'Art' of Entrepreneurship in Boot Camps,' in Journal of General Management, vol. 38, no. 1, pp. 45-71, Autumn 2012, doi: 10.1177/030630701203800103.

[6] C.L Moses, et al., "Quantitative Analysis of the Impact of Entrepreneurship Boot Camp on Training and Mentoring of Young Entrepreneurs," in Covenant Journal of Entrepreneurship (CJoE), vol. 1, no. 1, March 2018, doi: 10.21125/iceri.2016.0700. 
[7] National Science Foundation Innovation Corps (I-Corps ${ }^{\mathrm{TM}}$ ) Biennial Report. 2021. [Online] Available:

https://www.nsf.gov/news/special reports/i-

corps/resources.jsp [Accessed: Aug. 29, 2021]

[8] E. St-Jean, J. Audet, "The Role of Mentoring in the Learning Development of the Novice Entrepreneur," in International Entrepreneurship and Management Journal, November 2019, pp. 119-140. doi: 10.1007/s11365-009-01307.

[9] G. Ríos, "Innovación y Emprendimiento: Ingredientes para la Transformación Productiva," in Corporación Andina de Fomento (CAF), October 2018, [Online] Available: https://www.caf.com/es/conocimiento/visiones/2018/10/innov acion-y-emprendimiento-ingredientes-para-la-transformacionproductiva/ [Accessed: Aug. 29, 2021]

[10] "Emprendimiento en América Latina: la formación, la palanca del cambio," in International Center for Entrepreneurs Barcelona, September 2018, [Online] Available: https://www.iceb-edu.com/blog/emprendimientoamerica-latina-la-formacion-la-palanca-cambio [Accessed:

Aug. 29, 2021] 